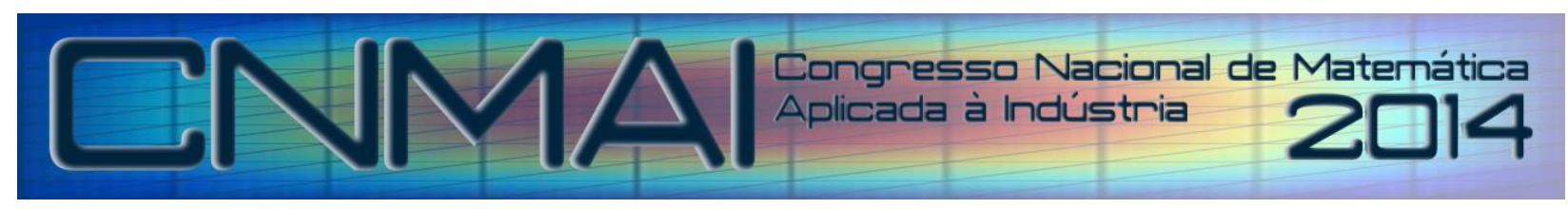

18 a 21 de novembro de 2014, Caldas Novas - Goiás

\title{
OTIMIZAÇÃO DO CONTROLE DA TEMPERATURA CENTRAL DE FORNO DE REDUÇÃO DE MINÉRIO EM RESPOSTA ÀS FLUTUAÇÕES NA VAZÃO DE ÓLEO COMBUSTÍVEL ALIMENTADA
}

\author{
Rubens Gedraite, rgedraite@feq.ufu.br ${ }^{1}$ \\ Fran Sérgio Lobato, fslobato@feq.ufu.br ${ }^{2}$ \\ Davi Leonardo de Souza, davilsouza@ gmail.com ${ }^{3}$ \\ ${ }^{1,2}$ UFU - Faculdade de Engenharia Química - Av. João Naves de Ávila, 2121 - Uberlândia/MG \\ ${ }^{3}$ UFTM - Departamento de Engenharia Química - Av.Randolfo Borges Jr., 1250, Uberaba/MG
}

\begin{abstract}
Resumo: $O$ trabalho descreve a aplicação de tecnicas de controle preditivo baseado em modelo e a otimização do controle de temperatura dos andares de um forno de redução de minério com base no emprego de modelos dinâmicos semi-empíricos obtidos com base nas curvas de reação do processo. A principal característica do processo estudado é a forte interação entre as variáveis de processo consideradas, o que dificulta muito o controle adequado das temperaturas. Foi analisada a influencia da variabilidade apresentada pela avzão de óleo combustível sobre as temperaturas dos andares 8,10 e 12, pelo fato de estarem intimamente relacionadas com as camaras de combustão do andar 11, que apresentou a maior variabilidade na vazao de óleo combustível. O aumento da eficiencia do forno na metalização do minério de niquel foi de aproximadamene 0,6\% e o desvio padrão máximo verificado nas temperaturas consideradas foi inferior $a 2,5^{\circ} \mathrm{C}$.
\end{abstract}

Palavras-chave: Forno Herreschoff, modelo preditivo multivariável, metalização de Niquel

\section{INTRODUÇÃO}

O processo Caron é uma rota hidrometalúrgica de produção de níquel que destina se à produção de níquel eletrolítico. Em uma primeira etapa, o minério já homogeneizado passa por uma britagem através de britador de rolo duplo, em seguida é britado e seco ao mesmo tempo num britador de martelos, e na sequência é moído em moinho de bolas em circuito fechado com ciclones. O minério moído e seco vai para os fornos de redução onde são adicionados gases redutores $\left(\mathrm{H}_{2}\right.$ e $\left.\mathrm{CO}\right)$, em seguida, é resfriado e encaminhado aos tanques de temperagem onde se adiciona solução amoniacal. A polpa sofre ação do ar, oxidando o níquel e o cobalto e estes passam para solução através do processo de lixiviação. Após esta etapa, $\mathrm{Ni}$ e Co são extraídos por decantação, a solução rica em níquel e cobalto é purificada e na sequência é encaminhada para torres de precipitação e secagem, obtendo-se o carbonato básico de níquel e cobalto. Após esta etapa é realizada a eletrólise para a obtenção de níquel e cobalto metálico. O processo Caron atualmente tem sua utilização limitada em função de altos custos por tonelada de níquel produzido, quando comparado a outros processos.

O forno utilizado neste processo é o forno Nicols-Herezonff, desenvolvido inicialmente a mais de 80 anos atrás para o processamento de minérios, sendo até hoje a principal aplicação para este tipo do forno. Sua utilização no beneficiamento de minério de níquel caracteriza-se por fornos verticais com vários andares e câmaras de combustão nos andares à base do forno. O forno é alimentado com ar e óleo combustível, e tem a função proporcionar as condições necessárias para a redução do minério, ou seja, gerar um perfil de temperatura adequado juntamente com um ambiente altamente redutor (rico em $\mathrm{CO}$ e $\mathrm{H}_{2}$ ). A Figura 1 apresenta uma representação simplificada deste forno. 


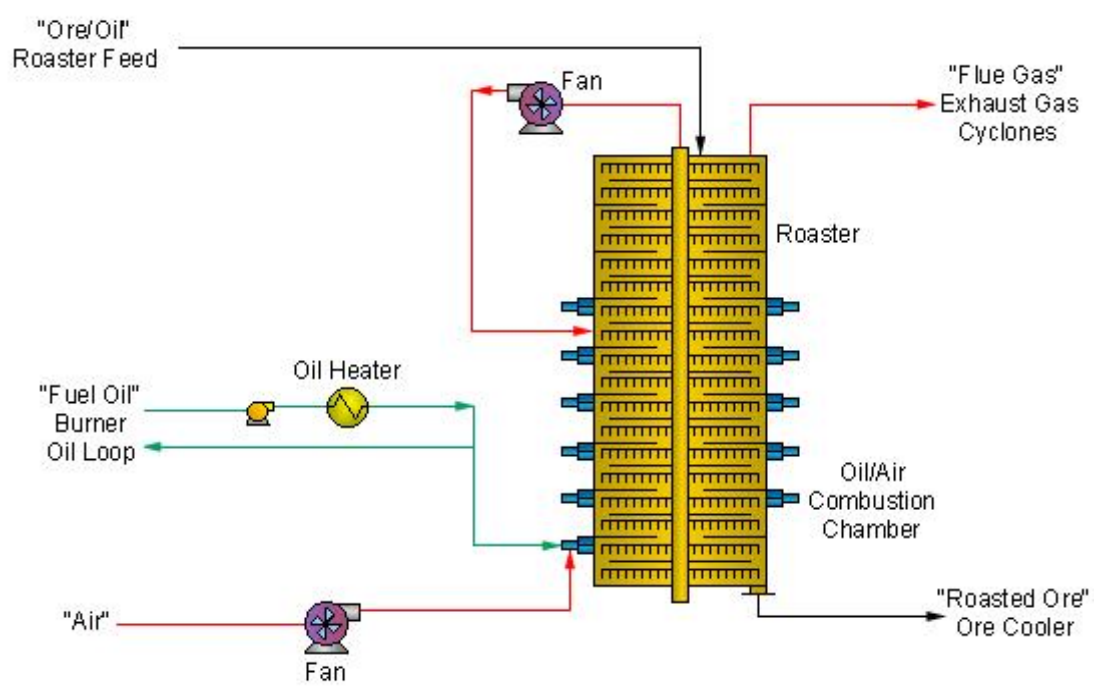

Figura 1. Representação esquemática do forno estudado.

\section{O CONTROLE DO PROCESSO DE REDUÇÃO DO MINÉRIO}

O controle do forno de redução de minério é executado com base nas temperaturas dos andares pares, que respondem pela meta estabelecida de metalização de Níquel e de Cobalto. Estas temperaturas são usadas como variáveis controladas pelo sistema de Controle Avançado do Processo (APC, em inglês).

O APC é responsável por definir os valores de set-point para os controladores de vazão de óleo combustível de cada uma das câmaras de combustão. Os valores de set-point das vazões de óleo são usados para calcular os correspondentes valores estequiométricos das vazões de ar de combustão a serem alimentados às respectivas câmaras, multiplicando estes valores por um fator constante que é definido em função do poder calorífico do combustível.

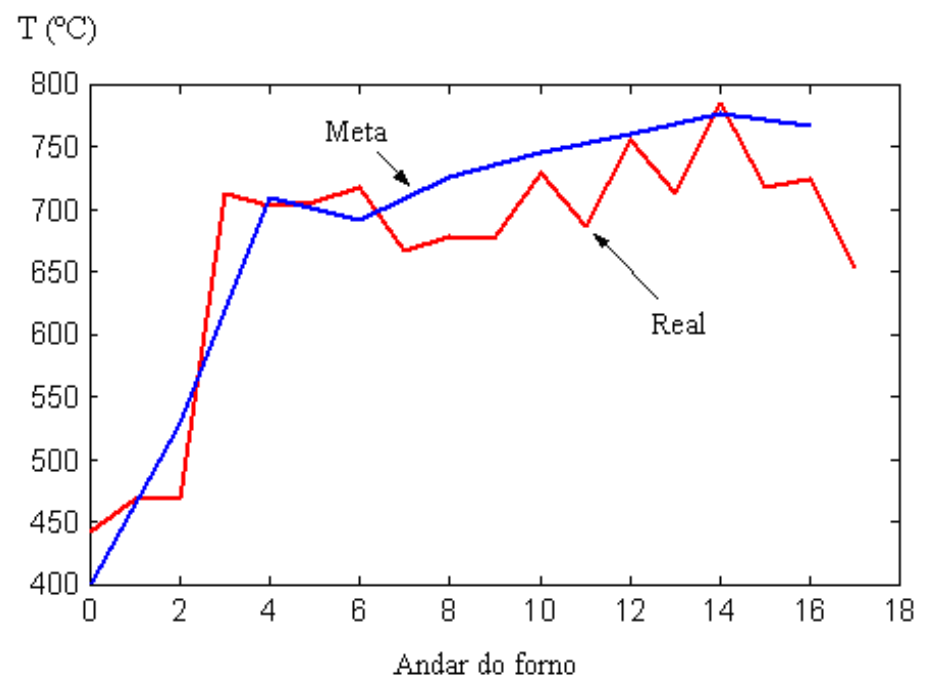

Figura 2. Perfil de temperatura do forno.

O sinal de vazão real de ar de combustão - medida por meio de um transmissor de vazão que opera com base no princípio da dispersão termal - é dividido pelo sinal de vazão estequiométrica de ar de combustão, obtendo-se desta maneira um fator empírico que está relacionado com a produção da atmosfera redutora no interior dos fornos. Da prática industrial, foi estabelecido que este fator devesse ser inferior à unidade e estar compreendido entre 0,4 e 0,8 .

Os sinais correspondentes aos fatores empíricos são usados como variáveis de processo dos controladores de razão ar/óleo combustível, os quais - por sua vez - recebem como valores de set-point os sinais provenientes dos controladores de temperatura das câmaras de combustão. A Figura 3 apresenta uma representação simplificada da malha de controle considerada.

Os controladores de razão ar/óleo combustível são responsáveis por definir os valores de vazão de ar a serem alimentados às respectivas câmaras de combustão, garantindo uma queima levemente incompleta. Esta condição é imprescindível para produzir uma atmosfera interna redutora nos fornos de redução. 


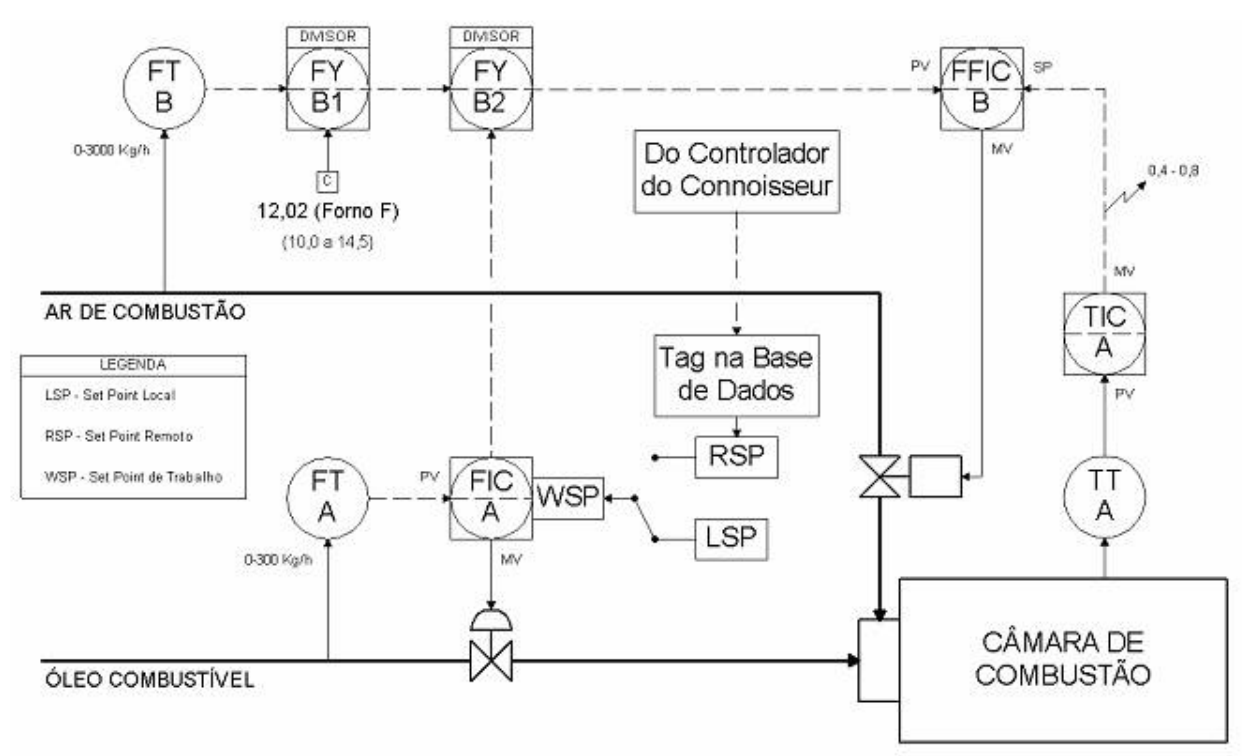

Figura 3. Malha de controle de temperatura do forno.

A principal função do APC é auxiliar o operador de processos na operação do equipamento industrial considerado sob condições ótimas. O APC alcança este objetivo operando em conjunto com o sistema de controle regulatório instalado na unidade. Este sistema de controle regulatório é composto por um sistema digital de controle distribuído baseado em controladores lógico-programáveis e por instrumentação de campo para as variáveis de processo vazão de óleo e vazão de ar de combustão. Neste cenário, é essencial que, tanto a instrumentação de processo como as malhas de controle regulatório estejam em boas condições de funcionamento para que o APC atue apropriadamente (Qin; Badgwell, 2003).

O pacote de otimização e de controle multivariável utilizado neste trabalho executa o controle preditivo multivariável considerando as restrições impostas pelos operadores para as temperaturas dos andares.

Os controladores preditivos multivariáveis (MPC, em inglês) necessitam de modelos empíricos de processo para executar a otimização do processo. Estes modelos são criados a partir de resultados obtidos ao se executar testes de resposta a degraus aplicados às variáveis de processo durante condições normais e estáveis de operação dos fornos de redução de minérios (Järvensivu et al., 2001).

O objetivo de controle específico do APC do forno de redução de minério estudado neste trabalho é levar o equipamento a operar de forma estável e segura, produzindo minério metalizado com a qualidade desejada, na taxa de produção pré-estabelecida e com a máxima eficiência, sem contudo permitir que ocorra a violação das limitações de processo que nele também encontram-se configuradas.

O MPC atua simultaneamente sobre as variáveis controladas e conduz o equipamento a seu ponto ótimo de funcionamento, compreendido entre os seus limites de operação e segurança, enviando set-points para as variáveis manipuladas em consonância com os respectivos limites máximos e mínimos especificados. O MPC utiliza um conjunto de modelos obtidos empiricamente como ferramenta de predição dos valores futuros das variáveis de controle e das correspondentes alterações a serem aplicadas às variáveis manipuladas. O MPC também monitora a variação sofrida pelas variáveis feedforward, buscando compensar os seus efeitos (Vieira et al., 2013).

Quando o processo requer que a variável controlada esteja compreendida entre os limites máximos e mínimos, o APC mostrará MIN/MAX. Nos casos em que for necessário que a variável controlada persiga uma meta especificada, o APC mostrará SP.

A função das variáveis do tipo restrição é definir uma região com os limites de operação para o controlador MPC, evitando que este ajuste as variáveis manipuladas em valores que levem o Forno a operar em regime indesejado. Por exemplo, a temperatura de saída do produto do forno é incluída como uma variável com restrição de valor alto, pois esta é uma preocupação dos operadores.

A interface de comunicação APC com a base regulatória foi feita através do link de comunicação OPC, usando um aplicativo OPC Server existente e instalado no microcomputador fornecido pelo fabricante do sistema de controle que compõe a base regulatória, e um segundo aplicativo $O P C$ Client instalado no microcomputador que receberá o aplicativo do APC para o controle avançado dos fornos (SIMSCI-ESCOR, 2005).

Foram configuradas telas gráficas para a operação do aplicativo do APC de cada forno, além daquelas normais de operação já previstas no sistema de controle que compõe a base regulatória. Estas telas são do tipo texto-tabular, que permite a interação com o operador através de cursor para entrada dos valores a serem ajustados. 


\section{ESTUDO DA DINÂMICA DA PLANTA}

A dinâmica da planta foi obtida a partir da identificação não-paramétrica, a qual fez uso das curvas de resposta do processo quando excitados por sinais de entrada do tipo degrau. A partir dessas curvas, podem-se extrair modelos aproximados, de baixa ordem, que descrevam o comportamento dinâmico do processo (Aguirre, 2007). Esses modelos são razoavelmente precisos e podem ser assumidos como suficientes para se ter uma ideia bastante adequada da resposta do sistema estudado. Neste trabalho, eles foram utilizados para modelar matematicamente o comportamento dinâmico das temperaturas dos andares números 8, 10 e 12 do forno estudado em função do tempo, tendo-se optado por ajustar um modelo de $1^{\mathrm{a}}$ ordem com atraso de transporte para cada curva do comportamento da temperatura em função da variação de vazão de óleo combustível.

A Tabela 2 apresenta os resultados experimentais consolidados para os parâmetros obtidos para estes modelos.

Tabela 2. Parâmetros dos modelos do processo estudado.

\begin{tabular}{cccc}
\hline Andar & $\begin{array}{c}\text { Ganho Processo } \\
\left({ }^{\circ} \mathrm{C} /(\mathrm{kg} / \mathrm{h})\right)\end{array}$ & $\begin{array}{c}\text { Constante de tempo } \\
(\mathrm{seg})\end{array}$ & $\begin{array}{c}\text { Atraso de transporte } \\
(\mathrm{seg})\end{array}$ \\
\hline \hline 8 & 3,5049 & 785,99 & 273,88 \\
10 & 10,0337 & 238,39 & 91,65 \\
12 & 4,0937 & 1202,4 & 12,80 \\
\hline
\end{tabular}

\section{ESTUDO DA VARIABILIDADE}

A avaliação do desempenho da planta passa necessariamente pelo conhecimento do comportamento da mesma tanto no estado estacionário quanto no estado dinâmico. No estado estacionário é interessante a avaliação de como as variáveis de processo importantes para o acompanhamento e controle do processo flutuam em torno do valor usual de operação.

Um processo que apresente elevada variabilidade necessita ser mais bem avaliado de modo a permitir uma intervenção mais direta sobre as causas raízes que são as responsáveis pelo comportamento indesejado do sistema.

Neste trabalho foi feita uma análise de variabilidade nas malhas de controle de vazão de óleo combustível, por ser este o insumo mais caro no processo. Existem diferentes maneiras de se quantificar a variabilidade apresentada pelo processo, a saber (Laaksonen; Pyötsiä, 1998):

a) Medir a máxima variabilidade do sinal de saída do processo;

b) Calcular ao longo do tempo a área do erro entre o valor de referência e a variável medida, usando técnicas IAE Integrated Absolute Error ou ISE - Integrated Square Error;

c) Duplicar o valor do desvio padrão do erro $(\sigma)$ e dividi-lo pelo valor médio da saída do processo $(\mu)$, isto é, calculando $(2 . \sigma / \mu)$; ou ainda

d) Duplicar o valor do desvio padrão do erro (2. $\sigma)$.

O critério adotado para avaliar a variabilidade apresentada pelas variáveis de processo consideradas neste trabalho baseou-se no critério de duplicar o valor do desvio padrão e dividir o valor obtido pelo valor da média (McMillan, 1994).

A variabilidade é uma grandeza que representa o comportamento de variáveis, dando uma noção do quanto elas variam ao longo do tempo. Uma análise nas vazões de ar e de óleo combustível (variáveis manipuladas pela malha de controle) que alimentam as câmaras de combustão do forno foi realizada, onde se constatou elevados valores de variabilidade na vazão de óleo combustível para determinadas câmaras. Para que fosse realizada tal análise, foram medidos experimentalmente os valores de vazão de óleo combustível, durante uma jornada típica de operação do forno (Gouveia et al., 2009). O resultado é apresentado na Figura 5. Optou-se por analisar o comportamento das câmaras 5 e 6 , por estarem estas localizadas no mesmo andar do forno considerado ( $11^{\circ}$ andar $)$ e interferirem mais diretame nte com as temperaturas dos andares 8,10 e 12 .

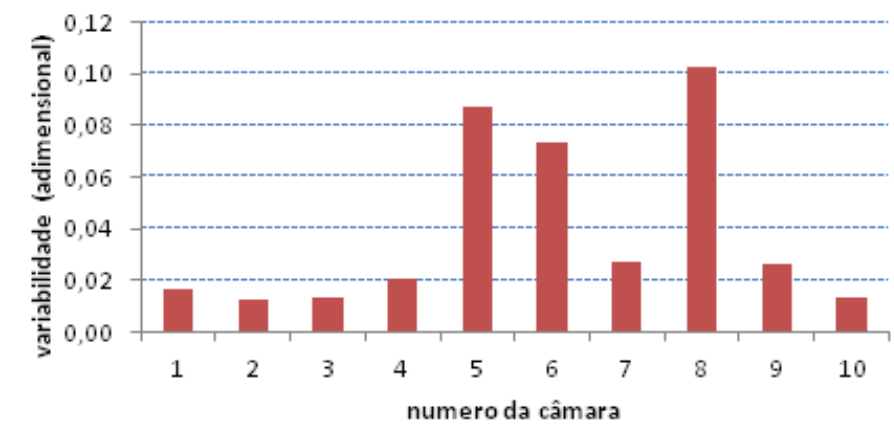

Figura 5. Variabilidade na vazão de óleo combustível alimentado às câmaras. 
Nos gráficos apresentados nas figuras 6 e 7 são mostrados os comportamentos temporais dos valores do desvio da vazão de óleo combustível para as câmaras 5 e 6 do Forno E respectivamente.

A partir destes dados foi calculado o valor médio para cada vazão e o respectivo desvio padrão. Com base nestes valores, foi calculado o valor da variabilidade, onde se constatou elevados valores de variabilidade para algumas câmaras. Visando aperfeiçoar a operação do forno e entender os motivos da ocorrência desta situação foi realizado um estudo específico para o $11^{\circ}$ andar do Forno E. Deve ser ressaltado o fato de que os modelos simplificados do processo foram obtidos de acordo com a metodologia usada na análise de curvas de resposta de sistemas (Aguirre, 2007) e foram implementados no ambiente Simulink ${ }^{\circledR}$ do aplicativo Matlab®, como apresentado na figura 8.

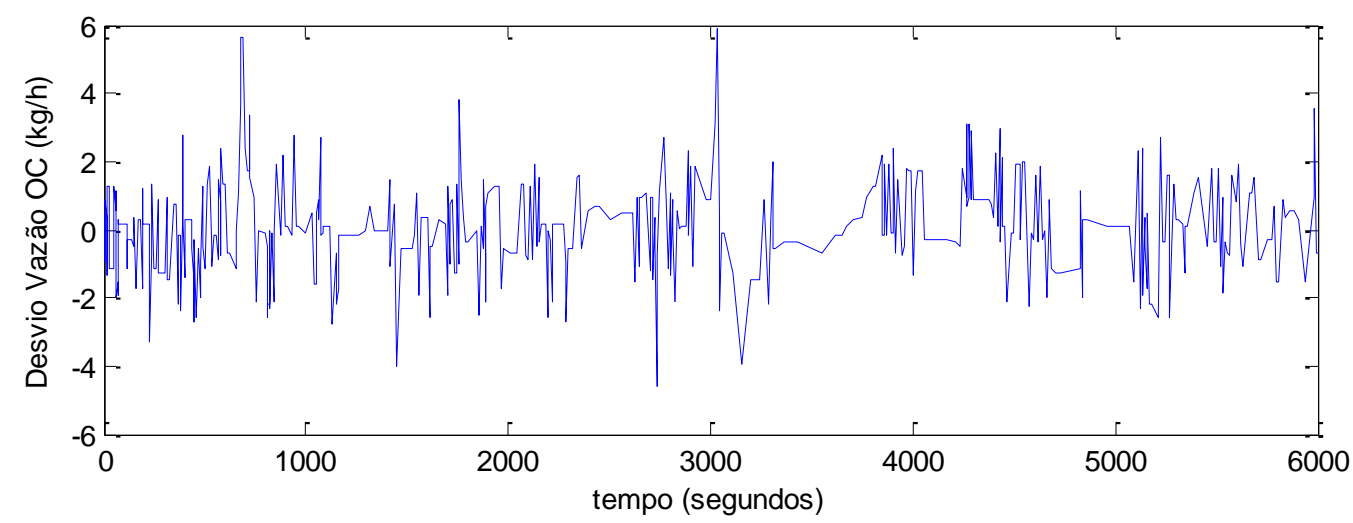

Figura 6. Comportamento temporal do desvio na vazão de óleo combustível para a câmara 5.

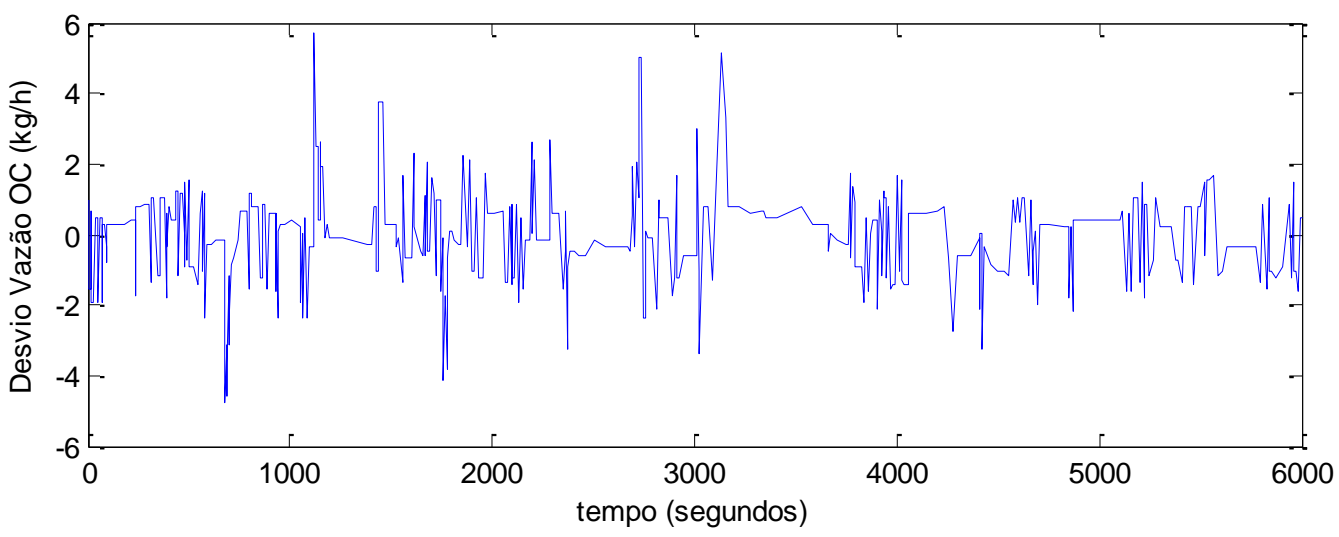

Figura 7. Comportamento temporal do desvio na vazão de óleo combustível para a câmara 6.

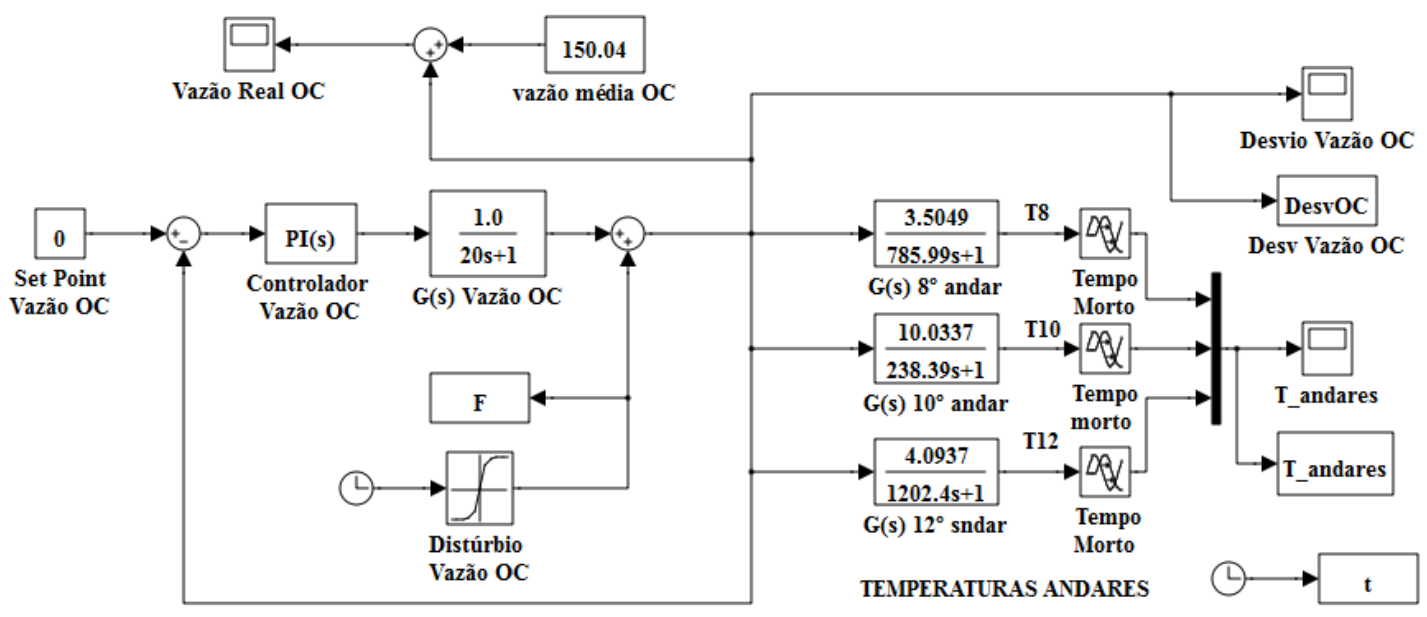

Figura 8. Modelo empírico do processo estudado. 
Com base nos resultados experimentais obtidos, foi considerado para efeito de simulação o comportamento variável da vazão de óleo alimentada às câmaras 5 e 6, expressas em termos de variável desvio, como mostrado nas Figuras 6 e 7 respectivamente.

\section{RESULTADOS OBTIDOS}

Os resultados apresentados neste trabalho foram obtidos com base em análises estatísticas utilizando o aplicativo EXCEL ${ }^{\circledR}$. Os dados experimentais foram obtidos em operações ensaios realizados na instalação industrial. Foram calculados a média e o desvio padrão das variáveis de processo consideradas como indicadores de melhoria de desempenho dos fornos. Na tabela 3 é apresentado um resumo dos resultados obtidos para alguns dos fornos existentes. Neste trabalho foi considerado o Forno E.

Tabela 3. Resultados obtidos para a metalização do níquel.

\begin{tabular}{ccc}
\hline FORNO & Parâmetro & $\begin{array}{c}\text { Variação obtida com } A P C \\
{[\%]}\end{array}$ \\
\hline \hline E & Metalização de Níquel & $+0,618$ \\
G & Metalização de Níquel & $+0,362$ \\
H & Metalização de Níquel & $+1,566$ \\
I & Metalização de Níquel & $+3,541$ \\
\hline
\end{tabular}

As variáveis de saída do modelo são as temperaturas dos andares 8, 10 e 12 do forno estudado, expressas na forma de variáveis desvio. As temperaturas simuladas apresentaram o comportamento temporal mostrado nas Figuras 11 e 12 em resposta às perturbações aplicadas.

$\mathrm{Na}$ tabela 4 são apresentados os valores calculados para as médias e desvios padrão correspondentes às temperaturas dos andares considerados em resposta às variações no valor da vazão de óleo combustível na câmara 05 e na tabela 5 são apresentados os mesmos valores calculados para as temperaturas dos andares considerados em respostas às variações no valor da vazão de óleo combustível na câmara 06.

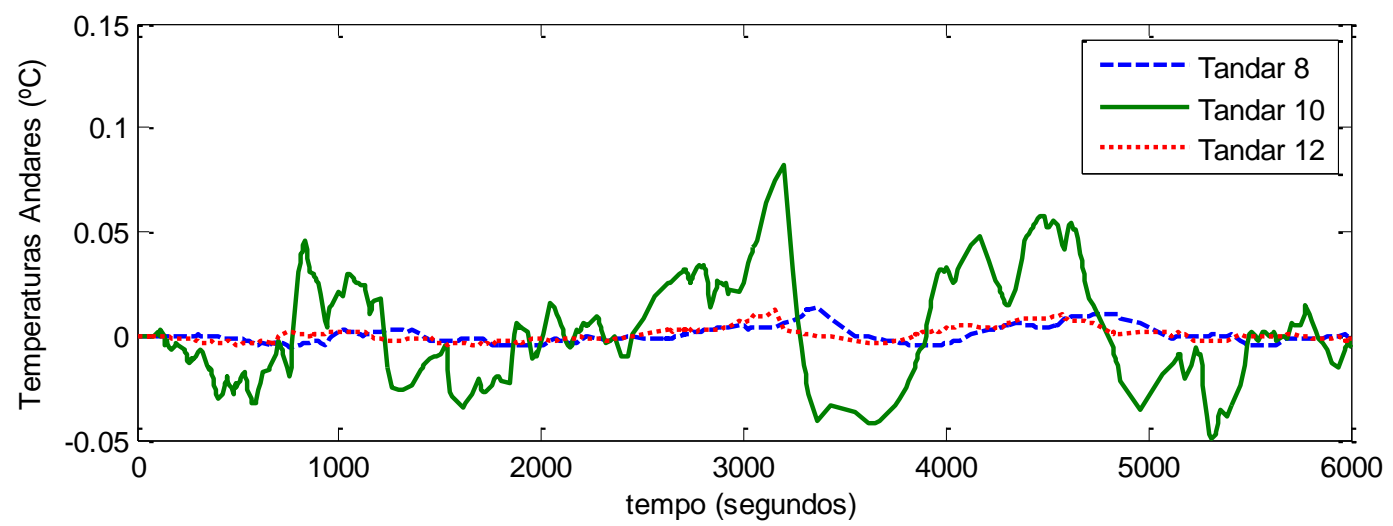

Figura 11. Comportamento temporal das temperaturas dos andares selecionados para flutuações na vazão de óleo combustível alimentadas na câmara 5 do forno $\mathrm{E}$.

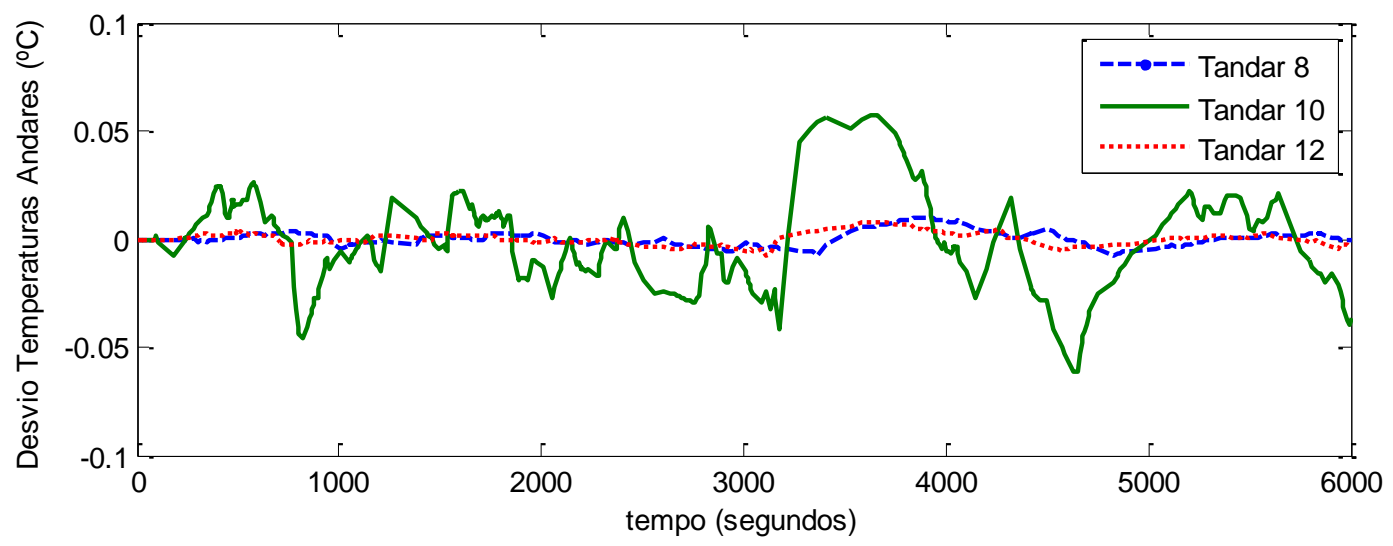

Figura 12. Comportamento temporal das temperaturas dos andares selecionados para flutuações na vazão de óleo combustível alimentadas na câmara 6 do forno $E$. 
Tabela 4. Resultados obtidos para os desvios na temperatura dos andares em resposta à variações na vazão de $\mathrm{OC}$ na câmara 05 .

\begin{tabular}{cccc}
\hline & T $8^{\circ}$ andar & T $10^{\circ}$ andar & T $12^{\circ}$ andar \\
\hline \hline Média $\left({ }^{\circ} \mathrm{C}\right)$ & $-0,044$ & 0,262 & 0,003 \\
Desvio Padrão $\left({ }^{\circ} \mathrm{C}\right)$ & 0,356 & 2,370 & 0,329 \\
\hline
\end{tabular}

Tabela 5. Resultados obtidos para os desvios na temperatura dos andares em resposta à variações na vazão de $\mathrm{OC}$ na câmara 06.

\begin{tabular}{cccc}
\hline & T $8^{\circ}$ andar & T $10^{\circ}$ andar & T 12 andar \\
\hline \hline Média $\left({ }^{\circ} \mathrm{C}\right)$ & 0,00065 & 0,001325 & 0,0000656 \\
Desvio Padrão $\left({ }^{\circ} \mathrm{C}\right)$ & 0,003514 & 0,02141 & 0,002682 \\
\hline
\end{tabular}

\section{DISCUSSÃO DOS RESULTADOS}

Os resultados obtidos mostraram que as perturbações verificadas nas vazões de óleo combustível alimentadas nas câmaras de combustão de números 5 e 6 , localizadas no $11^{\circ}$ andar do forno, geraram diferentes respostas de variação de temperaturas para cada um dos andares analisados.

Com base nos resultados obtidos, constata-se que as temperaturas dos andares 8, 10 e 12 foram afetadas pelos distúrbios nos valores de vazão de óleo combustível, em que pese o fato de que os desvios máximos e mínimos verificados foram de pequena amplitude. Tal comportamento era esperado, visto que o APC estava ativo e tinha como meta manter as temperaturas dos andares nos respectivos valores pré-ajustados.

O fluxo dos gases quentes gerados na combustão tende a subir pelo forno, provocando tanto o aquecimento dos andares acima daquele no qual as câmaras de combustão estudadas estavam localizadas quanto o aquecimento do minério que é transportado do topo para a base do forno.

O minério mais quente transporta consigo maior quantidade de energia (entalpia de transporte), a qual será responsável por provocar a variação nas temperaturas dos andares inferiores. Não existe no equipamento industrial uma forma de se medir a vazão de minério que é transferido por gravidade de um andar para outro. Este fato impossibilita uma avaliação exata da quantidade de energia transportada pelo minério, bem como a sua distribuição espacial em cada andar do forno.

\section{CONCLUSÕES}

A avaliação do comportamento temporal das temperaturas dos andares do forno com base nos dados experimentais utilizados mostrou ser muito difícil assegurar valores estáveis para as variáveis consideradas na presença dos distúrbios postulados. As características específicas de operação do equipamento de processo, tais como: limpeza das câmaras de combustão, variação da qualidade do minério alimentado ao equipamento e eventuais flutuações nos valores da vazão de óleo combustível e/ou de ar de combustão alimentadas ao forno, acabam por interferir nas temperaturas dos andares.

Os valores relativamente elevados obtidos para as variabilidades das temperaturas dos andares mostram que, de fato, estas sofrem variações constantes de valor em torno do valor estabelecido como target pelo sistema de controle avançado.

As causas raízes das oscilações no valor das vazões de óleo combustível alimentadas às câmaras de combustão ainda esta sendo investigadas. A natureza incrustante do óleo combustível, aliada à agressividade do ambiente de operação, tais como atmosfera com temperatura ambiente elevada e vibração no próprio equipamento de processo, poderiam afetar a medição.

\section{AGRADECIMENTOS}

Os autores agradecem à UFU - Universidade Federal de Uberlândia e à empresa Invensys pelo apoio no desenvolvimento deste trabalho.

\section{REFERÊNCIAS BIBLIOGRÁFICAS}

Aguirre, L. A., 2007. Introdução à identificação de sistemas: técnicas lineares e não lineares aplicadas a sistemas reais. Ed. UFMG.

Gouveia, R. M.; Lewis, D. G.; Restrepo, A.; Rodrigues. L. A. and Gedraite, R. 2009. Application of Model-Predictive Control to Multi-Hearth Nickel Reduction Roasters. Proceedings of IFAC. Chile.

Järvensivu, M.; Saari, K.; Jämsä-Jounela, S.-L. Intelligent Control system of an industrial lime kiln process. 2001. USA. Control Engineering Practice 9 (2001) 589- 606. 
Laaksonen, J.; Pyötsiä, J. 1998. Process variability simulated, tested, minimized. In Tech, v.45, n.12, p.68-70, Dec.

McMillan, G. K. Tuning and control loop performance. $3^{\text {rd }}$ ed., Research Triangle Park, NC, ISA - The Instrumentation, Systems and Automation Society, 1994.

Qin, S. J., Badgwell T. A. 2003. A Survey of Industrial Model Predictive Control Technology. - Control Engineering Practice, Vol. 11, 2003, 733-764.

Vieira, L., Rodrigues, L. A., Gedraite, R., Neiro, S. M. S. e Morais, A. S. 2013. Considerações práticas sobre controle avançado de processo aplicado a moinho de bolas. Anais do XXV Encontro Nacional de Tratamento de Minérios e Metalurgia Extrativa \& VIII Meeting of the Southern Hemisphere on Mineral Technology, Goiânia - GO, 20 a 24 de Outubro 2013

SIMSCI-ESCOR. 2005. CONNOISSEUR Multivariable Process Control Software Manual. USA.

\title{
RESPONSABILIDADE AUTORAL
}

Os autores são os únicos responsáveis pelo conteúdo deste trabalho.

\section{OPTIMIZATION OF ORE REDUCTION ROASTER CENTRAL TEMPERATURE CONTROL IN RESPONSE TO FLUCTUATIONS IN THE FUEL OIL FEED FLOW RATE}

\author{
Rubens Gedraite, rgedraite@feq.ufu.br ${ }^{1}$ \\ Fran Sérgio Lobato, fslobato@feq.ufu.br ${ }^{2}$ \\ Davi Leonardo de Souza, $\underline{\text { davilsouza@ @mail.com }}{ }^{3}$
}

${ }^{1,2}$ UFU - Faculdade de Engenharia Química - Av. João Naves de Ávila, 2121 - Uberlândia/MG

${ }^{3}$ UFTM - Departamento de Engenharia Química - Av.Randolfo Borges Jr., 1250, Uberaba/MG

\begin{abstract}
The paper describes the application of techniques of model predictive control and optimization of temperature control of an oven floors ore reduction based on the use of semi-empirical dynamic models obtained based on the reaction curves of the process. The main feature of the case study is the strong interaction between the process variables considered, which greatly impedes the proper temperature control. Fuel oil flow rate variability was analyzed concerning the temperatures of floors 8, 10 and 12, because they are closely related to the combustion chambers of the 11th floor, which present the highest variability in the fuel oil flow rate. The increased efficiency of the furnace in nickel ore reductio process was aproximatelly $0.6 \%$ and the maximum standard deviation observed at temperatures considered was less than $2.5^{\circ} \mathrm{C}$.
\end{abstract}

Keywords: Nickel metallization, multivariable, model-predictive, Herreschoff roaster 